\title{
FARMACOLOGIA E TOXICOLOGIA DO ÁCIDO ASCÓRBICO: UMA REVISÃO
}

\author{
Maria Caroline Jacques da Silva \\ Departamento de Química -CCNE \\ UFSM -Santa Maria - RS
}

\section{ABSTRACT}

L-Ascorbic acid (AA) or vitamin $C$ is a six carbon cetolactone, structurally related to glucose and other hexoses. The major sources of $A A$ are citrus fruits, strawberry, melon, green pepper, potato, tomato and leafy green vegetables. AA interferes with a broad spectrum of oxidation-reduction reactions, acting in at least 10 enzymatic systems. In this way, vitamin C influences the synthesis of collagen, carnitine, and neurotransmitters; the transformation of cholesterol into bile acids; biotransformation of xenobiotics substances; absorption of iron; and formation and scavenging of oxygen free radicals. AA is used as food addictive because of its antioxidant properties. Terapeutically, it is used as nutricional supplement during scurvy. Human beings and other primates, as well as guinea pigs and some species of bats are mammals that are unable to synthesize $A A$; thus, they need $A A$ in the diet to prevent scurvy. Rats are able to synthesize AA using glucose, through intermediary formation of D-glucuronic acid, L-gulonic acid and Lgulonolactone. Homo sapiens lack the hepatic enzyme gulonolactone 
oxidase, which catalyses the last reaction of the biosynthesis pathway (Lgulonolactone conversion to ascorbic acid). The functions of central nervous, immune, and cardiovascular systems, and the periodontal tissue, as well as the detoxification function of the liver, are negatively influenced by vitamin C deficiency. In this way, it has been described several benefits of vitamin supplement ingestion, as decreasing of LDL cholesterol, including megadoses that can reach as much as $18 \mathrm{~g}$ daily. Although there have been raised many literature about vitamin $C$ use in a wide variety of diseases, there is a lack of clinical efficiency of megadoses; besides, some side effects can come up, as diarrhea and oxalate stones in the kidneys. However, the ideal daily intake of vitamin $C$ is still unknown. This happen because the recommended daily intake is based in a single role of $A A$, the scurvy prevention. Daily ingestion of AA should be the same quantity excreted or destroyed by oxidation, taking into consideration $A A$ actions on the enzymatic systems. Actually, vitamin $C$ is necessary for health in little quantities and is harmful in large doses. It happens because the cells are always walking a balance between oxidation and reduction processes, and $A A$ in great quantities assume oxidative characteristics, interfering in this balance. Although the existence of several evidences indicating AA toxicity in large doses, there are some authors who believe that the ingestion of large doses is safe, but they admit that the disposable data are very contradictory.

\section{RESUMO}

O L-ácido ascórbico (AA) ou vitamina $C$, é uma cetolactona de 6 carbonos, estruturalmente relacionada com a glicose e outra hexoses. As fontes de $A A$ na dieta são as frutas cítricas, morango, melão, pimentão verde, repolho, batata, tomate e vegetais de folhas verdes. O AA atua em reações de oxi-redução em pelo menos 10 sistemas enzimáticos. Dessa maneira, a vitamina $C$ tem influência na síntese do colágeno, carnitina e 
neurotransmissores; transformação de colesterol em ácidos biliares; biotransformação de xenobióticos; absorção do ferro; formação e neutralização de radicais livres de oxigênio. Por suas propriedades antioxidantes, o AA é usado como aditivo alimentar. Terapeuticamente, é usado como suplemento nutricional durante estados de deficiência da vitamina, que é o caso do escorbuto. Os seres humanos e outros primatas, bem como as cobaias e alguns tipos de morcego são os únicos mamíferos conhecidos incapazes de sintetizar o AA; em conseqüência, necessitam da vitamina $C$ na dieta para a prevenção do escorbuto. $O$ rato sintetiza o ácido ascórbico a partir da glicose, através da formação intermediária de ácido Dglicurônico, ácido L-gulônico e L-gulonolactona. O homem não possui a enzima hepática gulonolactona oxidase, que faz a última reação da via de sintese, que é a conversão da L-gulonolactona em ácido L-ascórbico. As funções dos sistemas nervoso, imune e cardiovascular, o tecido periodontal assim como a função de detoxificação do fígado são negativamente influenciados pela deficiência de vitamina $\mathrm{C}$. Assim, têm sido relatados vários benefícios da ingestão de suplementos da vitamina, inclusive de megadoses que podem alcançar até $18 \mathrm{~g}$ diárias, como diminuição do colesterol LDL. Apesar de ter surgido uma extensa literatura a respeito da aplicação da vitamina $\mathrm{C}$ em uma grande variedade de doenças, há uma falta de eficácia clínica das megadoses, além de alguns efeitos colaterais que podem surgir, como diarréia e cálculos de oxalato nos rins. No entanto, a dose diária ideal de vitamina $\mathrm{C}$ ainda é desconhecida. Isso porque a dose diária recomendada atualmente baseia-se em uma única função do $A A$, a de evitar o escorbuto. $A$ ingestão diária de $A A$ deve ser igual à quantidade excretada ou destruída pela oxidação, levando em conta os sistemas enzimáticos nos quais a vitamina atua. $\mathrm{Na}$ verdade, a vitamina $\mathrm{C}$ é necessária para a saúde em pequenas quantidades e danosa em grandes doses. Isso acontece porque as células estão em constante manutenção de seus processos de oxidação e redução, e o AA em grande quantidade assume características oxidativas, 
interferindo então neste equilibrio. Apesar de várias evidências indicando a toxicidade do AA em altas doses, também há autores que afirmam que a ingestão de grandes doses de vitamina $\mathrm{C}$ é segura, apesar de admitir que os dados disponíveis são muito contraditórios.

\section{HISTÓRICO}

O escorbuto, doença causada pela deficiência de vitamina C, tem sido conhecido desde o tempo das cruzadas, sobretudo entre as populações do norte da Europa, que se alimentavam com dietas deficientes em frutas e legumes durante extensos períodos do ano. $A$ incidência da doença diminuiu com a introdução da batata (fonte de vitamina C) na Europa, no século XVII. Entretanto, as longas viagens marinhas de exploração durante os séculos $\mathrm{XVI}$ ao XVIII, que eram empreendidas sem suprimentos de frutas e vegetais frescos, resultavam em morte de grande número de membros das tripulações por escorbuto (GOODMAN \& GILMAN, 1996).

Há muito tempo suspeitava-se de uma causa alimentar para o escorbuto. Todavia, um estudo sistemático só se iniciou em 1747, quando individuos com escorbuto receberam vários tipos de alimentos (cidra, vinagre, água do mar, limão e laranja, alho, mostarda), determinados por Lind, um médico da British Royal Navy. Os que receberam frutas cítricas recuperaram-se rapidamente. Assim, foi introduzido o suco de limão nas grandes navegações a partir de 1800, reduzindo drasticamente o número de casos de escorbuto durante as expedições.

Outro episódio de grande significado na história da vitamina $\mathrm{C}$ foi o desenvolvimento de escorbuto em porcos da índia alimentados com aveia e farelo, sem vegetais frescos. Holst e Fröhlich descobriram assim um modelo animal adequado para o estudo da deficiência de $A A$, visto que posteriormente foi descoberto que a maioria dos mamíferos tem a capacidade de sintetizar esta vitamina; os seres humanos, os primatas não 
humanos, porcos da índia e certas espécies de morcegos de frutas na Índia são exceções. A demonstração de escorbuto na cobaia permitiu testar a potência antiescorbútica de frações de frutas cítricas. Em 1928, SventGyörgyi isolou um agente redutor na forma pura do repolho e das glândulas supra-renais; em 1932, Waugh e King identificaram o composto de SventGyörgyi como o fator antiescorbuto ativo no suco de limão. A estrutura química dessa substância foi logo estabelecida em vários laboratórios e atribui-se a denominação química comum de ácido ascórbico (AA) para referir-se à sua função na prevenção do escorbuto (GOODMAN \& GILMAN, 1996).

\section{CONCEITO E ESTRUTURA QUIMICA}

O L-ácido ascórbico, também conhecido como vitamina C, é uma cetolactona de 6 carbonos, estruturalmente relacionada com a glicose e outra hexoses. É a forma enólica da 2-oxo-L-gulofuranolactona e se oxida reversivelmente no organismo a ácido dehidroascórbico. A figura 1 mostra as estruturas dos ácidos ascórbico e dehidroascórbico.

O AA possui dois átomos de carbono opticamente ativos e a atividade antiescorbútica reside quase totalmente no isômero L. Uma das consequências da fácil oxidação do AA é a rapidez com que ele pode ser oxidado pela exposição ao ar, sobretudo em meio alcalino e na presença de cobre como catalisador (GOODMAN \& GILMAN, 1996). A vitamina se apresenta em forma cristalina, sólida e branca, facilmente hidrossolúvel. Soluções ácidas ( $\mathrm{pH}$ abaixo de 3) apresentam absorção máxima em $245 \mathrm{~nm}$, enquanto soluções da substância em sua forma ionizada ( $\mathrm{pH}$ maior que 5) apresentam pico de absorção em 265 nm. (BURTIS AND ASHWOOD, 1999). 


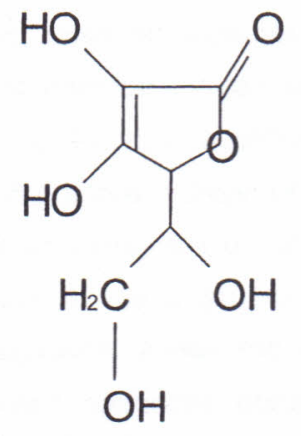

Ácido L-ascórbico

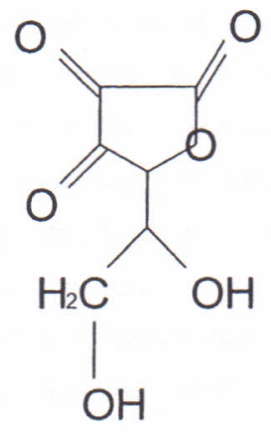

Ácido dehidroascórbico

Figura 1: Ácidos L-ascórbico e dehidroascórbico (BURTIS AND ASHWOOD, 1999).

\section{FONTES E FUNÇÕES}

As fontes de $A A$ na dieta são as frutas cítricas, morango, melão, pimentão verde, repolho, batata, tomate e vegetais de folhas verdes (MACHLIN, 1991). Os sucos de laranja e de limão são ótimas fontes e contém aproximadamente $0.5 \mathrm{mg} / \mathrm{ml}(2.8 \mathrm{mM}$ ) (GOODMAN \& GILMAN, 1996).

O AA funciona como cofator em diversas reações de hidroxilação e formação de amidas através da transferência de elétrons para enzimas que fornecem equivalentes redutores (LEVINE, 1986). Dessa maneira, ele é necessário ou facilita o metabolismo de drogas nos microssomas. De acordo com HORIO e YOSHIDA (1982), há várias 
possibilidades em relação aos efeitos do AA no sistema hepático de metabolização de drogas:

a) influência na síntese ou degradação do heme e hemeproteinas (P-450);

b) proteção do sistema de transporte de elétrons ou dos fosfolipídios na membrana do retículo endoplasmático;

c) supressão da peroxidação de lipídios na membrana do retículo endoplasmático;

d) manutenção do estado de oxi-redução de íons de ferro que participam no sistema de transporte de elétrons.

O papel mais claramente estabelecido para esta vitamina é o de cofator da protocolágeno hidroxilase, a enzima responsável pela hidroxilação de resíduos prolil e lisil dos peptídeos nascentes nas proteínas do tecido conectivo. Entre elas encontram-se o colágeno e proteínas relacionadas, como o material intracelular que compõe a cartilagem, dentina e ossos. A vitamina $C$ funciona de maneira similar na hidroxilação da $\gamma$ butirobetaina a carnitina (BURTIS AND ASHWOOD, 1999).

O escorbuto está associado a um defeito na síntese do colágeno, que se manifesta pela não cicatrização das feridas, por defeitos na formação dos dentes e na ruptura dos capilares, resultando em numerosas petéquias que coalescem, formando equimoses. Embora este último defeito tenha sido atribuido a um vazamento dos capilares em conseqüência da adesão inadequada das células endoteliais, acredita-se também que o tecido fibroso pericapilar esteja deficiente no escorbuto, levando a uma sustentação inadequada do capilar e à sua ruptura sob pressão (GOODMAN \& GILMAN, 1996).

O AA também pode estar envolvido no metabolismo da tirosina, síntese de epinefrina e esteróides antiinflamatórios pelas glândulas adrenais, metabolismo do ácido fólico (conversão em ácido folínico) e funções leucocitárias. O AA promove a atividade de uma enzima de 
formação de amidas que se acredita estar envolvida no processamento de certos hormônios peptídicos como a ocitocina, o hormônio antidiurético e a colecistocinina (LEVINE et al, 1993). Estas funções parecem estar relacionadas 'as propriedades redutoras do $A A$, especialmente em sistemas enzima- $\mathrm{Fe}^{2+}$. $\mathrm{A}$ absorção de ferro, como $\mathrm{Fe}^{2+}$, também é aumentada pela ingestão da vitamina, pois ela promove a redução do $\mathrm{Fe}^{3+}$ para $\mathrm{Fe}^{2+}$ no estômago, sendo a partir daí absorvido no intestino (BURTIS \& ASHWOOD, 1999).

\section{FUNÇÃO CEREBRAL DO ÁCIDO ASCÓRBICO}

O cérebro, medula espinhal e glândulas adrenais possuem as mais altas concentrações de ascorbato de todos os tecidos do corpo, assim como as maiores capacidades de retenção (HORNIG, 1975). No entanto, apesar das altas concentrações, as funções específicas do AA no sistema nervoso central estão apenas começando a serem elucidadas. Certamente, ele age como um antioxidante intracelular, e assim é normalmente tido como neuroprotetor. Também existe evidência de que o AA age como neuromodulador. Possivelmente, pode ter um único papel: o de agir como antioxidante no microambiente extracelular do cérebro, onde sua concentração é modulada pela troca entre glutamato e ascorbato nos sítios de captação do glutamato. Os estudos atuais sobre os transportadores de ascorbato e glutamato devem levar a um rápido progresso no entendimento da regulação e função do ascorbato (RICE, 2000).

\section{USOS}

O AA é usado como aditivo alimentar, inibindo reações enzimáticas de oxidação e protegendo o sabor e a cor naturais de muitos alimentos, como frutas e vegetais industrializados e laticínios (OGA, 1996). 
Terapeuticamente, é usado como suplemento nutricional durante estados de deficiência da vitamina, que é o caso do escorbuto. A necessidade de AA pode aumentar durante doenças crônicas, infecções, trauma, gravidez e lactação. Pode ser usado como acidificador da urina e supostamente promove uma cura para a gripe (WEXLER AND GAD, 1998). As propriedades redutoras da vitamina $C$ também tem sido empregadas para controlar a metemoglobinemia idiopática, embora ela seja menos eficaz que o azul de metileno. São necessárias doses diárias de pelo menos $150 \mathrm{mg}$ de AA para serem eficazes nessa condição.

O AA e outros nutrientes antioxidantes tem estado associados a proteção contra a formação de cataratas e a degeneração macular relacionadas com a idade (GERSHOFF, 1993). Dados obtidos pelo Estudo Longitudinal de Baltimore sobre o Envelhecimento sugeriram um efeito protetor pelo estado nutricional antioxidante global, inclusive da vitamina C, do $\alpha$-tocoferol e do $\beta$-caroteno (WEST et al., 1994). Os dados a partir de estudos publicados com relação às vitaminas, sais minerais e doenças oculares são promissores porém inadequados atualmente para apoiar as recomendações clínicas.

\section{VIAS DE ADMINISTRAÇÃO}

A vitamina $C$ é geralmente administrada por via oral; todavia, em condições onde a absorção adequada pelo trato gastrintestinal possa estar prejudicada, soluções parenterais podem ser administradas. Além disso, o AA deve ser administrado em pacientes que recebem hiperalimentação parenteral. Em virtude da perda urinária de grande parte do AA infundido, são necessárias doses diárias de 200mg para manter concentrações normais no plasma de cerca de $1 \mathrm{mg} / \mathrm{dl}(60 \mu \mathrm{M})$ nesses indivíduos (NICHOALDS et al., 1977). 


\section{FARMACOCINÉTICA}

O ácido ascórbico é absorvido no intestino por um mecanismo dependente de energia e de sódio, através de um sistema de transporte mediado por carreadores que é saturável (TOGGENBURGER et al., 1979). $\mathrm{Em} \mathrm{pH}$ fisiológico, o ácido dehidroascórbico não ionizado passa através das membranas celulares mais rapidamente que o L-ascorbato monoaniônico. A difusão passiva da vitamina $C$ contribui para sua entrada em algumas células, como leucócitos e eritrócitos, mas um mecanismo de transporte ativo também funciona, principalmente nas plaquetas, adrenais e retina. A difusão livre do ácido dehidroascórbico para o interior da célula, seguido de uma redução intracelular para um íon ascorbato menos difusível pode explicar a ocorrência de concentrações mais altas de ascorbato nos leucócitos que no plasma. A vitamina $\mathrm{C}$ é encontrada na maioria dos tecidos, mas as maiores quantidades encontram-se em tecidos glandulares, como o córtex das adrenais, a pituitária, corpo lúteo e timo, e a retina tem de 20 a 30 vezes a concentração plasmática (BURTIS AND ASHWOOD, 1999). As concentrações da vitamina nos leucócitos são algumas vezes consideradas como representativas das concentrações teciduais, sofrendo menor variação quando comparadas às concentrações plasmáticas. Os leucócitos de adultos saudáveis apresentam concentrações de cerca de $27 \mu \mathrm{g}$ de AA por $10^{8}$ células. Convém assinalar que a quantidade de AA existente nos leucócitos pode estar inversamente relacionada com seu número, de modo que as estimativas do nivel de AA podem ser falsamente baixas em pacientes com leucocitose, nos quais se determina a concentração de ascorbato nos leucócitos (VALLANCE, 1979). As concentrações plasmáticas também variam com a ingestão. Uma ingestão adequada está associada a concentrações superiores a $0.5 \mathrm{mg} / \mathrm{dl}(28 \mu \mathrm{M})$, enquanto concentrações de $0.15 \mathrm{mg} / \mathrm{dl}(8.5 \mu \mathrm{M})$ são observadas em indivíduos com escorbuto franco (GOODMAN \& GILMAN, 1996). 
A absorção do ascorbato dietético é quase completa, mas pode diminuir com o aumento da dose. Por exemplo, a absorção diminui de $75 \%$ com 1 grama administrada em uma única dose oral para $20 \%$ com 5 gramas (KALLNER et al., 1977).

A ligação às proteínas plasmáticas é de $25 \%$, e o ácido ascórbico é largamente distribuído pelos tecidos corporais. A meia vida da vitamina $\mathrm{C}$ no homem é de aproximadamente 16 dias. $\mathrm{O}$ ascorbato pode ser oxidado a $\mathrm{CO}_{2}$ em ratos e cobaias; contudo, a conversão é consideravelmente menor em seres humanos. Uma das vias do metabolismo no homem envolve a sua conversão em oxalato e ascorbato-2-sulfato (inativo), com excreção na urina. Também há presença de ascorbato, ácido dehidroascórbico e podem aparecer alguns açúcares, como 2,3-dicetogulonato e L-treonato, xilonato e lixonato (GOODMAN \& GILMAN, 1996, BURTIS AND ASHWOOD, 1999).

\section{BIOSSÍNTESE DO ÁCIDO ASCÓRBICO}

Os seres humanos e outros primatas, bem como porquinhosda-Índia e alguns tipos de morcego são os únicos mamíferos conhecidos incapazes de sintetizar o AA; em conseqüência, necessitam da vitamina $C$ na dieta para a prevenção do escorbuto. $O$ rato, tipicamente um animal que não requer a vitamina $\mathrm{C}$ dietética, sintetiza o ácido ascórbico a partir da glicose, através da formação intermediária de ácido D-glicurônico, ácido L-gulônico e L-gulonolactona. O homem não possui a enzima hepática gulonolactona oxidase, que faz a última reação da via de síntese, que é a conversão da Lgulonolactona em ácido L-ascórbico (Figura 2).

No decorrer da evolução, a atividade da gulonolactona oxidase diminuiu nos mamiferos mais evoluídos, o que foi acompanhado por um 
aumento na atividade da superóxido dismutase (SOD), outra enzima que atua na proteção contra o estresse oxidativo. No entanto, não se pode dizer que seus papéis são correspondentes, já que o $A A$ não é somente um neutralizador de ${ }^{1} \mathrm{O}_{2}$ e $\mathrm{O}_{2}{ }^{*-}$, mas também um protetor específico das membranas microssomais contra a peroxidação lipídica mediada pelo funcionamento das monooxigenases dependentes de citocromo P450 e degradação oxidativa de proteínas, funções para as quais a SOD é ineficaz (NANDI et al, 1997).

\section{DEFICIÊNCIA}

As funções dos sistemas nervoso, imune e cardiovascular, o tecido periodontal assim como a função de detoxificação do fígado são negativamente influenciados pela deficiência de vitamina C (GINTER, 1989).

Uma deficiência na ingestão de vitamina C pode provocar escorbuto. São observados casos de escorbuto em indivíduos alcoólatras, dependentes de drogas e outros com dietas inadequadas, incluindo lactentes. Em casos de escorbuto espontâneo, existe habitualmente afrouxamento dos dentes, gengivite e anemia, que pode ser devida a uma função específica do ácido ascórbico na síntese da hemoglobina. $\mathrm{O}$ quadro de escorbuto espontâneo na prática clínica freqüentemente é complicado por insuficiência também de outros nutrientes (GOODMAN \& GILMAN, 1996). A formação inadequada de substância intercelular no tecido conjuntivo se reflete em edema, supersensibilidade e até mesmo sangramento ou contusão local nas juntas ou outras áreas onde o tecido é fracamente estruturado e não suporta estresse (WINICK, 1987). Alguns pacientes com escorbuto podem desenvolver mudanças radiológicas características de osteoporose ou morte súbita por colapso cardíaco (BURTIS AND ASHWOOD, 1999). 


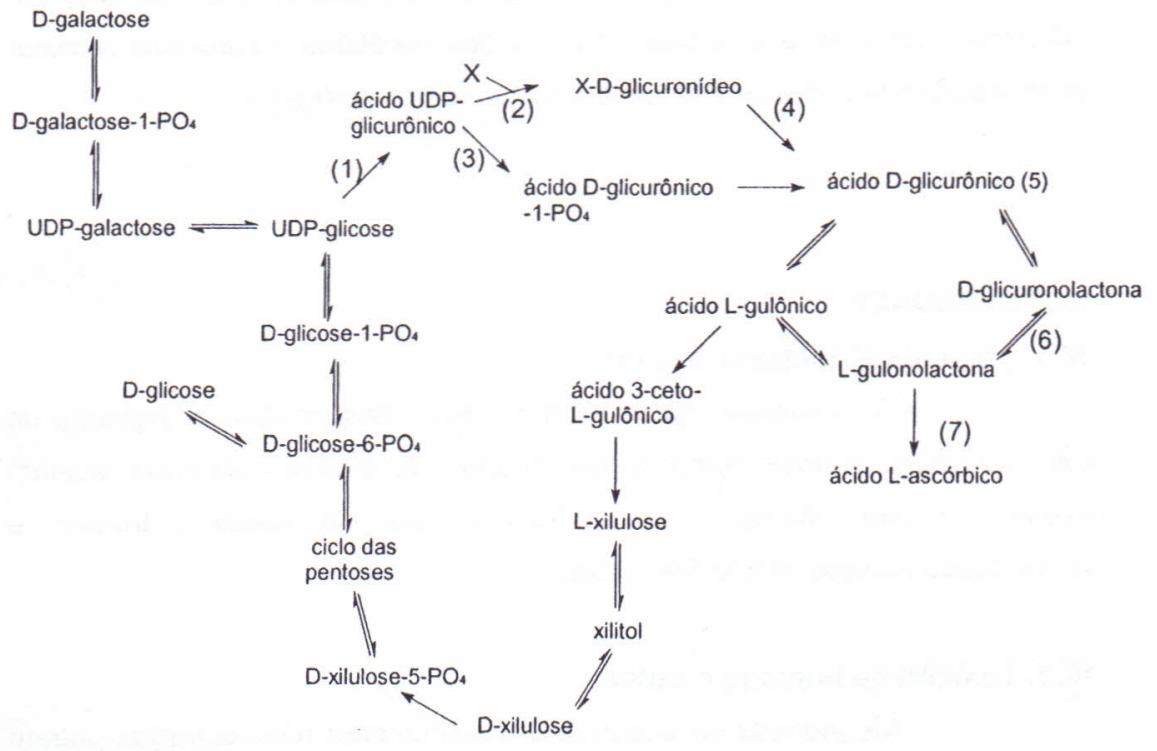

Figura 2: Via do ácido glicurônico. (1) UDP-glicose desidrogenase, (2) UDP-glicuronil transferase, (3) UDP-ácido glicurônico pirofosfatase, (4) $\beta$-glicuronidase, (5) conversão do ácido D-glicurônico a ácido L-ascórbico, (6) conversão de Dglicuronolactona a ácido L-ascórbico, (7) L-gulonolactona oxidase (HORIO et al., 1983).

O escorbuto infantil, também conhecido como Doença de Barlow, pode ocorrer em lactentes que recebem dietas com fórmulas preparadas em casa, com concentrações inadequadas de AA. O lactente mostra-se irritável e ressente-se ao ser tocado, em virtude da dor. A dor é causada por hemorragias sob o periósteo dos ossos longos e os hematomas resultantes freqüentemente são visiveis sob a forma de edema nas diáfises desses ossos (GOODMAN \& GILMAN, 1996). Podem aparecer pequenos sangramentos cutâneos, petéquias e equimoses devido ao rompimento dos 
capilares. Também já foram descritos hemorragia ocular, ressecamento das glândulas salivares e lacrimais, inchaço das parótidas, neuropatia femural, edema das extremidades inferiores e distúrbios psicológicos.

\section{TOXICIDADE}

\subsection{Toxicidade humana aguda:}

A toxicidade aguda é improvável, mesmo após a ingestão de até 100 vezes a dose diária recomendada. Os efeitos colaterais incluem náusea, vômito, diarréia, dor abdominal, dor de cabeça, tontura e vermelhidão da pele (WEXLER, 1998).

\subsection{Toxicidade humana crônica:}

Megadoses de vitamina $\mathrm{C}$ cronicamente administradas podem precipitar a formação de pedras de oxalato de cálcio no rim, neuropatia por oxalato e deficiência renal. A quantia necessária para causar esse efeito varia de 2 a $8 \mathrm{~g}$ por dia. Também já foi descrito depósito de oxalato nos ossos. Com a ingestão excessiva de tabletes é possível haver erosão no esôfago (WEXLER, 1998).

\subsection{Manejo clínico:}

Ingestão aguda requer tratamento. A diluição é recomendada para reduzir o risco de irritação gastrointestinal e esofágica. Durante uso crônico excessivo, os pacientes devem ser instruídos a descontinuar o suplemento e observar os sinais de escorbuto de rebote (WEXLER, 1998). Esse fenômeno de rebote é presumivelmente decorrente da indução de vias do metabolismo do $A A$ em conseqüência da dose elevada utilizada anteriormente (GOODMAN \& GILMAN, 1996). 


\section{BENEFÍcIOS DA INGESTÃo DE SUPLEMENTOS DE ÁCIDO ASCÓRBICO}

Estudos epidemiológicos encontraram baixa morbidade $\mathrm{e}$ mortalidade por doença coronariana cardíaca (DCC) em pessoas que ingeriam grandes quantidades de antioxidantes, como as vitaminas $C$ e $E$ na alimentação e suplementos. Evidências atuais sugerem que pacientes com DCC se beneficiariam da ingestão das vitaminas E e C nas doses de $400 \mathrm{UI}$ e 500-1000 mg/dia, respectivamente (ADAMS et al., 1999).

Um estudo publicado na revista Lancet em 1999 relata que o uso de 500 mg diários de vitamina $C$ é capaz de reduzir a pressão sangüínea em indivíduos com hipertensão leve a moderada, sem efeitos colaterais. Os testes foram realizados com 45 pacientes, num estudo duplo-cego com o uso de placebo. $O$ mesmo cientista também relata a existência de vários estudos que endossam o uso da vitamina $\mathrm{C}$ como suplemento alimentar:

- Uma revisão de mais de 200 artigos sobre os benefícios da vitamina $C$ para nossa saúde sugere que a ingestão de pelo menos 100 mg por dia está associada com uma incidência e mortalidade reduzida por doença cardíaca, infarto e câncer;

- Doses ainda maiores parecem ser necessárias para reduzir o risco de cataratas;

- Mais de 20 estudos clínicos têm mostrado que doses diárias de $500 \mathrm{mg}$ de vitamina $\mathrm{C}$ ou mais podeM aumentar significativamente a vasodilatação sangüínea em humanos; umA má dilatação dos vasos sangüíneos é fator de risco para angina pectoris e infarto;

- Os efeitos benéficos dos suplementos de vitamina C na normalização da vasodilatação tem também sido observados em pacientes com altos niveis de colesterol, angina, diabetes e fumantes;

- Um grande estudo epidemiológico publicado em 1992 mostrou uma redução no risco de doença cardíaca de $45 \%$ em homens e 25

Rev. Ciência e Natura, Santa Maria, 22: 103 - 128 , 2000. 
$\%$ em mulheres que consumiram aproximadamente $300 \mathrm{mg}$ diários de vitamina C, somando dieta e suplementos (Linus Pauling Institute Home Page).

Após administração de AA por um longo período de tempo a humanos com baixa quantidade plasmática de vitamina houve diminuição do colesterol total e LDL na maioria das pessoas. Também foi relatado que a administração de vitamina $\mathrm{C}$ a pessoas com distúrbios no metabolismo de lipoproteínas aumenta moderadamente o nivel de colesterol associado às lipoproteínas de alta densidade (HDL) (HEINE e NORDEN, 1979), efeito este provavelmente mediado pelo sistema P-450. Da mesma maneira, o AA também diminui os efeitos tóxicos do álcool etílico (ZANNONI et al., 1987) e bloqueia eficientemente a formação de compostos carcinogênicos $\mathrm{N}$-nitrosos no trato gastrointestinal (TANNENBAUM AND WISHNOCK, 1987).

Há experiências clínicas animadoras quanto ao uso do $A A$ para controle de pacientes com diabetes mellitus, doenças autoimunes e alergias (KODAMA e KODAMA, 1994). Testes com placebo têm mostrado que a suplementação com vitamina $\mathrm{C}$ diminui a duração e a severidade das infecções gripais (HEMILA, 1999).

Altos níveis de ácido ascórbico são encontrados no sangue de fetos prematuros e estes declinam rapidamente após o parto. A brusca redução sangüinea dos níveis de ascorbato nos bebês prematuros pode aumentar o risco de dano oxidativo, quais sejam displasia broncopulmonar e hemorragia intraventricular. Havia uma preocupação de que a administração de $A A$ aos bebês prematuros pudesse causar hemólise, mas em 1998, um estudo de BASS e colaboradores mostrou que a administração de AA é segura e garante as propriedades antioxidantes da vitamina.

Há apreensões de que a ingestão de altas quantidades de vitamina C poderia ter um impacto negativo em pacientes com hemocromatose pelo aumento da absorção de ferro (OLSON e HODGES, 1987). No entanto, há relatos de que esta suplementação com grandes 
quantidades de AA não influenciaria os estoques corporais de ferro, provavelmente devido a mecanismos homeostáticos eficientes (RIVERS, 1987 e HALBERG et al., 1987).

\section{NECESSIDADE DE MEGADOSES?}

A DDR (Dose Diária Recomendada) oficialmente aceita nos Estados Unidos, Grã-Bretanha e muitos outros países é de 30 a $60 \mathrm{mg}$ diários para adultos, enquanto que os defensores das megadoses recomendem até 600 vezes esta dose, isto é, $18000 \mathrm{mg}$ de AA (PAULING, 1986). O uso das megadoses de vitaminas em geral deve ser questionado, pelas seguintes razões:

1) faltam evidências científicas que sustentem a alegação do uso das megavitaminas em psiquiatria e outras desordens;

2) autoridades mundiais em nutrição e órgãos de regulamentação de medicamentos têm aprovado terapias vitamínicas apenas para tratamento ou prevenção de condições associadas a deficiências;

3) doses altas de vitaminas hidrossolúveis, como a vitamina $C$, são rapidamente excretadas pela urina, porém altas doses por tempo prolongado podem apresentar toxicidade. As lipossolúveis são depositadas e, portanto, podem causar mais efeitos colaterais quando ingeridas em altas doses (maiores que as DDR);

4) na ausência de diagnóstico de deficiência vitamínica, uma dieta balanceada contendo ampla variedade de alimentos de vários grupos nos dá todos os nutrientes necessários;

5) altas doses de vitaminas hidrossolúveis podem induzir a um estado de dependência, e sintomas de retirada podem aparecer quando o uso for descontinuado;

6) vitaminas podem mascarar os sinais e sintomas de doença preexistente (CIM/CRF, 1996). 
Nenhum suplemento é um antioxidante puro. Por exemplo, as vitaminas $C, E$ e o $\beta$-caroteno são na verdade agentes redox, istos é, antioxidantes em algumas circunstâncias (geralmente nas quantidades fisiológicas encontradas nos alimentos) e pró-oxidantes (podendo produzir radicais livres danosos) em outras circunstâncias (geralmente nas quantidades encontradas em suplementos) (HERBERT, 1994).

Apesar de ter surgido uma extensa literatura a respeito da aplicação da vitamina $\mathrm{C}$ em uma grande variedade de doenças, não existe evidência experimental da eficácia clínica das megadoses. Relatos esporádicos da eficácia da vitamina $\mathrm{C}$ na cura do câncer ou do resfriado comum não foram substanciados experimentalmente (GERSHOFF, 1993). Qualquer efeito preventivo que poderia ser derivado parece pequeno quando comparado ao custo e aos riscos das megadoses. Tais riscos incluem a formação de cálculos renais pela excreção excessiva de oxalato, escorbuto de rebote nos filhos de mães que ingerem doses elevadas e um fenômeno semelhante quando indivíduos que consomem grandes quantidades de $A A$ deixam de fazê-lo (GOODMAN \& GILMAN, 1996).

Alguns estudos relatam que os suplementos de vitamina $C$ são inúteis contra o câncer (BLOT, et al., 1993) e doença cardiaca (STEINBERG, 1993).

Como descrito anteriormente (BROWN, 1990, SAUBERLICH, 1994), grandes doses de AA têm sido geralmente consideradas atóxicas, exceto pelos sintomas gastrintestinais, que são experimentados por algumas pessoas; no entanto, efeitos adversos mais sérios já foram observados. Entre eles, destruição por redução de vitamina $B_{12}$ ingerida concomitantemente, facilitação excessiva da absorção de ferro, produção aumentada de oxalato favorecendo a deposição de pedras de oxalato de cálcio nos rins e bexiga e uricosúria (BURTIS AND ASHWOOD, 1999). Tanto os benefícios, em câncer e doenças cardíacas (SAUBERLICH, 1994), quanto 120 Rev. Ciência e Natura, Santa Maria, 22: $103-128$,2000. 
os riscos de altas doses de $A A$ parecem mínimos para a maioria das pessoas, que simplesmente excretam o excesso. No entanto, não se sabe nem mesmo se a excreção urinária indica saturação de AA (LEVINE et al., 1993).

Foi descrito que o AA pode causar diarréia em doses maiores que 3 a $4 \mathrm{~g}$ diárias, provoca resultados falso negativo para sangue oculto nas fezes e, pelo aumento da absorção de ferro, causar hemocromatose, talassemia maior e anemia sideroblástica. Pode causar hiperoxalemia em pacientes de diálise, hipersecreção de oxalato e cálculos renais para doses maiores que $4 \mathrm{~g}$ diárias e hiperuricosúria em doses intravenosas maiores que $2 \mathrm{~g}$. Quando grandes doses são ingeridas diariamente por vários meses ou anos, outros sintomas podem ocorrer, como uricosúria, reduzida atividade bactericida dos leucócitos, aumento da mobilização do cálcio ósseo, diminuição do tempo de coagulação sangüínea, diminuição dos níveis plasmáticos de vitamina $B_{12}$, interrupção da gravidez, diminuição da produção de insulina e interferência na terapia com anticoagulantes (OLSON AND HODGES, 1987).

Foi relatado que suplementos de vitamina $C$ podem dobrar o risco de doença cardiaca. Também pode se esperar que estes suplementos aumentem a mortalidade e câncer de pulmão em fumantes, já que a vitamina C retira a nicotina do sangue e manda para a urina (HERBERT et al., 1994), fazendo com que os fumantes procurem pelo próximo cigarro (mais carcinógenos) para manter seus altos níveis sangüineos de nicotina.

Os resultados de um estudo realizado por CHALMERS et al., em 1986, indicam que pacientes que freqüentemente formam pedras renais devem evitar a ingestão de altas doses de ascorbato. Pacientes com insuficiência renal ou em hemodiálise crônica também devem ser advertidos para não ingerir grandes quantidades da vitamina ( BALCKE et al., 1984). 
A vitamina $C$ torna-se especialmente perigosa na presença de grandes reservas de ferro, que a torna violentamente prooxidante (HERBERT, 1993). Nesse caso a vitamina aumenta a lipoperoxidação do colesterol associado às lipoproteínas de baixa densidade, que é extremamente danoso às artérias e coronárias (HERBERT et al., 1994). Estudos com peroxidação lipídica mostram que em níveis fisiológicos o ascorbato age primariamente como antioxidante; no entanto, adquire efeitos pró-oxidantes quando níveis farmacológicos são alcançados (SHAW et al., 1990).

Na presença de ferro, a vitamina $C$ é um dos pró-oxidantes mais potentes conhecidos (ZALESKA AND FLOYD, 1985). Aproximadamente $10 \%$ dos caucasianos e $8 \%$ dos afro-americanos nascem com um gene para absorção aumentada de ferro (hemocromatose heterozigota) e 1 em 250 têm dois genes para absorção aumentada de ferro (hemocromatose homozigota) (EDWARDS et al., 1991). O AA, que aumenta tanto a absorção de ferro como a liberação de ferro dos depósitos corporais, pode agir como o "segundo gene" nas pessoas homozigotas para a hemocromatose (HERBERT, 1992). Pelo aumento da absorção de ferro e liberação do ferro catalítico das reservas corpóreas, os suplementos de vitamina $\mathrm{C}$ podem ser extremamente danosos. Assim, antes de iniciar o uso de suplementos como a vitamina $\mathrm{C}$, recomenda-se verificar os níveis de ferro sérico. Com essa informação em mãos, pessoas com baixo ferro sérico poderiam se beneficiar do suplemento, ao contrário das pessoas com grande quantidade desse composto.

Megadoses da vitamina por via intravenosa podem matar pessoas geneticamente deficientes de glicose 6-fosfato desidrogenase, por hemólise oxidativa dos eritrócitos. Também pode precipitar crise aguda de falcização das hemácias em pessoas com anemia falciforme (COHEN AND SCHWARTZ, 1981).

122 Rev. Ciência e Natura, Santa Maria, 22: $103 \quad-128 \quad 2000$. 


\section{INDEFINIÇÕES QUANTO À DOSE DIÁRIA ADEQUADA}

\section{Qual é a dose de vitamina C que assegura um ótimo}

funcionamento dos sistemas nas quais ela interfere? A ingestão diária de AA deve ser igual à quantidade excretada ou destruída pela oxidação. Individuos adultos perdem 3 a 4\% da sua reserva corporal diariamente. Para manter uma reserva de $1500 \mathrm{mg}$ de AA ou mais em um homem adulto, seria necessária a absorção de 60 mg ao dia. (GOODMAN \& GILMAN, 1996).

A DDR adequada deveria se basear nas funções da vitamina $C$ nos sistemas biológicos e suas respostas ao aumento das doses do AA. Pelo menos 10 sistemas enzimáticos dependentes de AA são conhecidos: prolina hidroxilase ( $E C$ 1.14.11.2), lisina hidroxilase ( $E C$ 1.14.11.4), procolágenoprolina 2-oxoglutarato 3-dioxigenase (EC 1.14.11.7), gama-butirobetaína 2oxoglutarato 4-dioxigenase (EC 1.14.11.1), trimetillisina 2-oxoglutarato dioxigenase (EC 1.14.11.8), colesterol 7-alfa monooxigenase (EC 1.14.13.17), dopamina bea-monooxigenase (EC 1.14.17.1), 4hidroxifenolpiruvato dioxigenase (EC 1.13.11.27), peptidil glicina alfa amida monooxigenase e oxidases de função mista contendo o citocromo P-450. Alguns autores sugerem a quantificação da ingesta adequada de vitamina $\mathrm{C}$ pela medida in situ das taxas de reações enzimáticas em função da concentração de AA (LEVINE AND HARTZEL, 1987).

Em circunstâncias especiais, parece haver necessidade de maior quantidade de AA para a manutenção de concentrações plasmáticas normais. Os níveis plasmáticas inferiores da vitamina $C$ encontrados em fumantes resultam de uma taxa de modificação metabólica da vitamina. Assim, para assegurar um estado adequado da vitamina, a DDR para fumantes foi estabelecida em $100 \mathrm{mg} / \mathrm{dia}$ (Food and Nutrition Board, 1989). As concentrações de ascorbato no plasma também são reduzidas pelo uso de agentes anticoncepcionais orais. As necessidades podem aumentar em 
determinadas doenças, particularmente as doenças infecciosas e também após uma cirurgia (LEVINE et al., 1993).

A quantidade de AA necessária para aliviar e curar os sinais clínicos de escorbuto é de $10 \mathrm{mg} / \mathrm{dia}$. No entanto, essa quantia não é necessária para as reservas. Uma DDR de $60 \mathrm{mg}$ parece adequada para manter as reservas teciduais de um homem adulto perto da saturação, já que possui um "pool" corporal de aproximadamente $1.5 \mathrm{~g}$. Somente quando o "pool" cai abaixo de $300 \mathrm{mg}$ os sintomas clínicos de deficiência ocorrem (HODGES et al, 1971). Para suprir as necessidades fetais, é recomendado para a mulher grávida um adicional de $10 \mathrm{mg} /$ dia para compensar a diminuição do nivel plasmático da vitamina $C$ durante a gravidez. Mulheres amamentando devem receber um adicional de 30 a $35 \mathrm{mg} / \mathrm{dia}$, porque uma média de 18 a $22 \mathrm{mg}$ pode ser secretada em 600 a $700 \mathrm{ml}$ de leite. Lactentes devem receber $35 \mathrm{mg} / \mathrm{dia}$. Uma QDR maior de $100 \mathrm{mg}$ é sugerida para prematuros e recém nascidos na primeira semana para a proteção contra uma possível tirosinemia (BURTIS AND ASHWOOD, 1999).

\section{CONCLUSÕES}

Por seus diversos papéis fisiológicos, a vitamina C é um antioxidante essencial. No entanto, a DDR atual é baseada em um único papel do $A A$, que é o de evitar o escorbuto. Assim, vários estudiosos defendem o uso de megadoses desta vitamina. Na verdade, como foi descrito neste artigo, a vitamina C é uma "faca de dois gumes", necessária para a saúde em pequenas quantidades e danosa em grandes doses. Isso acontece porque as células estão em constante manutenção de seus processos de oxidação e redução, e o AA em grande quantidade assume características oxidativas, interferindo então neste equilíbrio. 
Apesar de várias evidências indicando a toxicidade do AA em altas doses, também há autores que afirmam que a ingestão de grandes doses de vitamina C é segura (RIVERS, 1987), apesar de admitir que os dados disponíveis são muito contraditórios. A extensão real na qual grandes doses de AA podem prejudicar a saúde de maneiras irreparáveis não é conhecida, já que a freqüência do relato de manifestações tóxicas é muito pequena em relação a quantidade de pessoas que ingere estas megadoses. Isso acontece principalmente porque as pessoas não são bem orientadas quanto ao uso de suplementos alimentares, tanto os vitamínicos como os minerais, e assim, em uma consulta médica, dificilmente irão relacionar os sintomas que sentem com a ingestão destes suplementos. Assim como grande parte das plantas medicinais, eles não são considerados pela população em geral como medicamento. Suplementos podem ajudar algumas pessoas, causar danos a outras e não provocar efeitos na maioria.

AGRADECIMENTOS: CNPq/PIBIC. 


\section{REFERÊNCIAS BIBLIOGRÁFICAS:}

ADAMS, A. K., WERMUTH, E. O., MCBRIDE, P. E. Antioxidant vitamins and the prevention of coronary heart disease. Am. Fam. Physician. 60:895904 (1999).

BALCKE, P., SCHMIDT, P., ZAZGORNIK, J., KOPSA, H. \& HAUBENSTOCK, A. Ascorbic acid aggravates secondary hyperoxalemia in patients on chronic hemodialysis. Ann. Inter. Med. 101:344-345 (1984).

BASS, W. T., MALATI, N., CASTLE, M. C., WHITE, L. E.. Evidence for the safety of ascorbic acid administration to the premature infant. Am J Perinatol. 15:133-40 (1998).

BLOT, W. J., LI, J. Y. , TAYLOR, P. R., GUO, W., DAWSEY, S., WANG, G. Q., YANG, C. S., ZHENG, S. F., GAIL, M. AND LI, G. Y. Nutrition intervention trials in Linxiam, China: supplementation with specific vitamin/mineral combinations, cancer incidence, and disease-specific mortality in the general population. J. Natl. Cancer Inst. 85:1483-92 (1993).

BROWN, M. L. Ed.: Present Knowledge in nutrition, $6^{\text {th }}$ ed. Washington, DC, International Life Sciences Institute -Nutrition Foundation, 1990.

BURTIS, C. A., ASHWOOD, E., Eds: Tietz Textbook of Clinical Chemistry, $3^{\text {rd }}$ ed., W. B. Saunders Company, pp. 1023-1025 (1999).

CHALMERS, A. H., COWLEY, D. M. \& BROWN, J. M. A possible etiological role for ascorbate in calculi formation. Clin. Chem. 32:333-336 (1986).

CIM/CRF-PR (Centro de Informação de Medicamentos). Boletim informativo $n^{\circ} 003$, out-nov/1996.

COHEN, A., SCHWARTZ, E. Vitamin C and iron overload. New Engl. J. Med. 304: 1108 (1981).

DUFFY, S. J., GOKCE, N., HOLBROOK, M., HUANG, A., FREI, B., KEANEY, J. F. JR, VITA, J. A. Treatment of hypertension with ascorbic acid. Lancet 354:2048-2049 (1999).

EDWARDS, C. Q., GRIFFEN, L. M., KUSHNER, J. P. Disorders of excess iron. Hosp. Pract., 26 (supl): 30-36 (1991).

GERSHOFF, S. N. Vitamin C (ascorbic acid): new roles, new requirements? Nutr. Rev.51:313-326 (1993).

GINTER, E. Ascorbic acid in cholesterol metabolism and in detoxification of xenobiotic substances: problem of optimum vitamin intake. Nutrition, 5:369-374 (1989).

GOODMAN \& GILMAN. As Bases Farmacológicas da Terapêutica $9^{a}$ ed., Ed Mc Graw Hill, pp 1161-1163 (1996).

HALLBERG, L., BRUNE, M., ROSSANDER-HULTHÉN, L. Is there a physiological role of vitamin C in iron absorption? Ann. NY Acad. Sci. 498:324 (1987). 
HEINE, H., NORDEN, C. Vitamin C therapy in hyperlipoproteinemia. Int. J. Vitam. Nutr. Res. 19 (Supl):45 (1979).

HEMILA, H. Vitamin C supplementation and common cold symptoms: factors affecting the magnitude of the benefit. Med Hyp 52:171-8 (1999).

HERBERT, V. Dangers of iron and vitamin C supplements. J. Am. Diet. Assoc. 93:526-7 (1993).

HERBERT, V. Iron disorders can mimic anything, so always test for them. Blood Ver. 3:125-132 (1992).

HERBERT, V., SHAW, S., JAYATILLEKE, E. Vitamin C supplements are harmful to lethal for the over $10 \%$ of Americans with high iron stores. FASEB J._8: A678 (1994).

HERBERT, V. The antioxidant supplement myth. Am. J. Clin. Nutr._60:157158 (1994).

HODGES, R. E., HOOD, J., CANHAM, J. E., SAUBERLICH, H. E., BAKER, E. M. Clinical manifestations of ascorbic acid deficiency in man. Am. J. Clin. Nutr. 24:432-443, (1971).

HORIO, F. AND YOSHIDA, A. Effects of some xenobiotics on ascorbic acid metabolism in rats. J. Nutr. 112:416-425 (1982).

HORIO, F., KIMURA, M., YOSHIDA, A. Effect of several xenobiotics on the activities of enzymes affecting ascorbic acid synthesis in rats. J. Nutr. Sci. Vitaminol. 29, 233-247 (1983).

HORNIG, D. Distribution of ascorbic acid, metabolites and analogues in man and animals. Ann. N. Y. Acad. Sci. 258, 103-117 (1975).

KALLNER, A., HARTMAN. D., AND HORNIG, D. On the absorption of ascorbic acid in man. Int. J. Vitam. Nutr. Res. 47:383-388 (1977).

KODAMA, M, KODAMA, T: Is Linus Pauling, a vitamin $\mathrm{C}$ advocate, just making much ado about nothing? In Vivo 8: 391-400 (1994).

LEVINE, M. New concepts in the biology and biochemistry of ascorbic acid. N. Engl. J. Med., 314:892-902 (1986).

LEVINE, M., CANTILENA, C.C. AND DHARIWAL, K. R. In situ kinetics and ascorbic acid requirements. World Ver. Nutr. Diet. 72:114-127 (1993).

LEVINE, M., HARTZELL, W. Ascorbic acid: the concept of optimum requirements. Ann. N. Y. Acad. Sci. 498:424-444 (1987).

LINUS PAULING INSTITUTE HOME PAGE: http://www.orst.edu/dept/lpi/

MACHLIN, L. J. Ed.: Handbook of vitamins, $2^{\text {nd }}$ edition New York, Marcel Dekker, Inc. (1991)

NANDI, A., MUKHOPADHYAY, C. K., GHOSH, M. K., CHATTOPADHYAY, D. J., CHATTERJEE, I. B. Evolutionary significance of vitamin C biosynthesis in terrestrial vertebrates. Free Rad. Biol. Med. 22: 1047-54 (1997).

NICHOALDS, G. E., MENG, H. C. AND CALDWELL, M. D. Vitamin requirements in patients receiving total parenteral nutrition. Arch. Surg. 112: 1061-1064 (1977).

OGA, S. Fundamentos de toxicologia -São Paulo: Atheneu Editora de São Paulo (1996).

Rev. Ciência e Natura, Santa Maria, 22: $103-128$, 2000. 
OLSON, J. A., HODGES, R. E. Recommended dietary intakes (RDI) of vitamin C in humans. Am. J. Clin. Nutr. 45:693-703 (1987).

PAULING, L. How to live longer and feel better. New York: William H. Freeman (1986).

RICE, M. E. Ascorbate regulation and its neuroprotective role in the brain. Trends Neurosci. 23, 209-216 (2000).

RIVERS, J. M. Safety of high-level vitamin C ingestion. Ann. N. Y. Acad. Sci. 498: 445-454 (1987).

SAUBERLICH, H. E.: Pharmacology of vitamin C. In: Annual Review of Nutrition, Vol. 14, R. E. Olson, Ed. Palo Alto, CA, Annual Reviews, Inc.(1994).

SHAW, S., HERBERT, V., COLMAN, N., JAYATILLEKE, E. Effect of ethanolgenerated free radicals on gastric intrinsic factor and glutathione. Alcohol 7:153-7 (1990).

STEINBERG, D. Antioxidant vitamins and coronary heart disease. N. Engl. J. Med. 328: 1487-9 (1993).

TANNEMBAUM, S. R., WISHNOK, J. S. Inhibition of nitrosamine formation by ascorbic acid. Ann. N. Y. Acad. Sci. 498: 354-363 (1987).

TOGGENBURGER, G., LANDOLDT, M. \& SEMENZA, G. Na ${ }^{+}$-dependent, electroneural $\mathrm{L}$-ascorbate transport across brush border membrane vesicles from human small intestine: Inhibition by D-erythorbate. FEBS Lett., 108: 473-476 (1979).

VALLANCE, S. Leucocyte ascorbic acid and the leucocyte count. Br. J. Nutr. 41:409-411 (1979).

WEST, S., VITALE, S., HALLFRISCH, J., MUÑOZ, B., MULLER, D., BRESSLER, S., AND BRESSLER, N. M.. Are antioxidants or supplements protective for age-related macular degeneration? Arch. Ophtalmol. 112:222-227 (1994).

WEXLER, P., Editor. Enciclopedia of Toxicology. Ed. Academic Press (1998).

WINICK, M.: Nutrition in Health and Disease. New York, John Wiley \& Sons, Inc., Chapters 8 and 9 (1987).

ZALESKA, M. M., FLOYD, R. A. Regional lipid peroxidation in rat brain in vitro: possible role of endogenous iron. Neurochem. Res. 10: 397-410 (1985).

ZANNONI, V. G., BRODFUEHRER, J. I., SMART, R. C. SUSICK, R. L. Jr. Ascorbic acid, alcohol, and environmental chemicals. Ann. N. Y. Acad. Sci. 498: 364-368 (1987). 